\title{
A TRANSFORMAÇÃO DA EDUCAÇÃO JURÍDICA NO SECULO XXI: A FORMAÇÃO DAS COMPETÊNCIAS PROFISSIONAIS DOS OPERADORES DO DIREITO
}

\author{
Isadora K. Lazaretti* \\ Giovanni Olsson ${ }^{* *}$
}

\section{RESUMO:}

Este artigo visa analisar a transformação da educação jurídica no século XXI com base na formação das competências profissionais dos operadores do Direito. Com a crise do ensino jurídico, manifestada pela proliferação elevada de cursos de Direito, os números de reprovados no Exame de Ordem e a quantidade de profissionais desempregados, essa investigação mostra-se relevante e complexa. Especificamente, busca-se diagnosticar a crise do ensino do Direito; compreender o fenômeno globalizante e a sociedade em rede; e, por fim, compreender a gestão de competências como uma nova proposta. Como procedimentos metodológicos, adotou-se o método indutivo, utilizando-se a técnica de pesquisa bibliográfica.

Palavras-chave: Educação jurídica; formação profissional; competências; conhecimento, habilidades; atitudes.

\section{THE TRANSFORMATION OF LEGAL EDUCATION IN THE 21st CENTURY: THE FORMATION OF THE PROFESSIONAL COMPETENCES OF LAW OPERATORS}

\begin{abstract}
:
This article aims to analyze the transformation of legal education in the 21 st century based on the formation of professional skills of legal operators. With the crisis of legal education, manifested by the high proliferation of law courses, the numbers of failing in the Order Exam and the number of unemployed professionals, this investigation proves to be relevant and complex. Specifically, we seek to diagnose the crisis of law teaching; understand the globalizing phenomenon and network society; and finally, to understand competency management as a new proposal. As methodological procedures, the inductive method was adopted, using the technique of bibliographic research.
\end{abstract}

Keywords: Legal Education; professional qualification; Competences; knowledge, skills; attitudes.

\section{INTRODUÇÃO}

\footnotetext{
* Doutoranda em Direito pela Universidade do Oeste de Santa Catarina (UNOESC). Endereço postal: Av. Herculano H. Zanuzzo, n. 632, Seara-SC, CEP 89770-000. E-mail: isadoralazaretti@hotmail.com

** Doutor em Direito pela Universidade Federal de Santa Catarina (UFSC). Professor do Programa de PósGraduação em Direito da Unochapecó. Endereço postal: Rua Senador Atilio Fontana, Efapi, Chapecó-SC, 89809-900. E-mail: golsson71@gmail.com
} 
O presente artigo analisa a crise do ensino do Direito no Brasil e a sua transformação a partir da gestão de competências na formação profissional dos operadores do Direito no século XXI. Diante da proliferação do ensino jurídico e do aumento elevado do número de cursos de graduação em Direito nos últimos anos, somado às estatísticas preocupantes de reprovações no Exame da Ordem e da atual crise do mercado de trabalho desses profissionais, o estudo se mostra necessário, e constitui um tema complexo e ao mesmo tempo contemporâneo, uma vez que enfrenta uma realidade que está em curso no âmbito social.

O objetivo central deste artigo é apresentar a ideia de que a crise da educação jurídica exige uma mudança paradigmática do ensino do Direito, a partir da instituição de gestão de competências para o aperfeiçoamento da formação profissional dos operadores do Direito. A formação profissional dos operadores jurídicos, ainda no curso de graduação, deve considerar muitas variáveis, indo além do ensino teórico e seu relacionamento com a prática, mas, explorar o conhecimento, as habilidades e as atitudes do profissional, elementos que não são veiculados no modelo de formação acadêmica atual. De modo específico, este estudo tem como tarefa: diagnosticar a crise do ensino jurídico no Brasil; compreender a sociedade globalizada em rede; e, por fim, estudar a gestão de competências com uma nova proposta de reorientação ao ensino jurídico.

Caminhos diversos podem ser apontados para sua análise, e o presente estudo apresenta pesquisa que pretende revelar a conexão entre a crise da educação jurídica no Brasil e o modo de qualificação dos profissionais do Direito durante o curso da graduação. A investigação funda-se na mudança paradigmática da formação exclusivamente acadêmica do profissional, baseada na correlação da teoria e da prática, sendo, contudo, necessário o desenvolvimento de uma educação para o mercado de trabalho e efetivo exercício da profissão, com base no desenvolvimento e na exploração de competências profissionais.

Para tanto, o estudo se divide em três tópicos estruturantes. O primeiro deles, aborda o diagnóstico da crise na educação jurídica no Brasil, apontando a atual situação do ensino jurídico e estatísticas que comprovam essa realidade em números. O segundo tópico versa sobre a emergência do fenômeno da globalização e da sociedade em rede, cuja realidade se manifesta na era contemporânea e exerce influência para a transformação do ensino do Direito no país. Por fim, o terceiro e último tópico, estuda uma nova proposta de reorientação como possível solução ou melhoria dos efeitos da crise da educação jurídica, a partir da instituição de uma gestão de competências, pautada no conhecimento, nas habilidades e nas atitudes. 
Os procedimentos metodológicos adotados para a realização dessa pesquisa consistiram no método dedutivo, sendo a pesquisa de caráter qualitativo, tendo sido adotada a técnica de pesquisa bibliográfica para sua elaboração.

\section{O DIAGNÓSTICO DA CRISE DA EDUCAÇÃO JURÍDICA}

Não é nenhuma surpresa a afirmação da crise na educação jurídica no Brasil. Ainda em 1955, com a aula inaugural da Faculdade Nacional de Direito por San Tiago Dantas, a educação jurídica era discutida sob o viés da crise. Esses debates se acentuaram ao longo dos anos, de modo que desde a década de 70, já se verificaram uma série de críticas ao modelo de ensino do Direito existente no país, especialmente no que diz respeito às questões metodológicas e curriculares. Para Rodrigues e Junqueira, nessa época, “floresce uma crítica de matiz política, voltada aos próprios conteúdos e valores reproduzidos pelo Ensino do Direito" (2002, p. 31).

Desde então, estratégias foram traçadas para estabelecer as diretrizes essenciais ao desenvolvimento do ideário de educação jurídica, com a finalidade da formação de profissionais com aptidões e competências no mercado de trabalho, assim como juristas comprometidos com a função e a transformação social. O período compreendido entra os anos de 1970 a 1980 foi o que houve maior número debates, propostas e movimentos direcionados à implementação de mudanças para resolver os problemas da educação jurídica (RODRIGUES e JUNQUEIRA, 2002, p. 31).

San Tiago Dantas, ao proferir a aula inaugural na Faculdade Nacional de Direito, afirmou que é por meio da educação jurídica "que uma sociedade assegura o predomínio dos valores éticos perenes na conduta do indivíduo e sobretudo órgãos do poder público". Contudo, não se pôde deixar de perceber que o Direito, enquanto um instrumento de regulação da sociedade, passou a perder espaço e prestígio perante outras técnicas e instrumentos, dotadas de elevado grau de eficiência que o Direito em si (SAN TIAGO DANTAS, 1955, p.6).

Verificou-se uma massificação acelerada e desqualificada dos cursos de Direito, que despertou na comunidade acadêmica um relevante debate sobre a estruturação metodológica e dos currículos jurídicos. Instaurou-se, assim, uma crise na estrutura da educação jurídica, afetando seu funcionamento e sua operacionalidade (RODRIGUES e JUNQUEIRA, 2002, p. 
35). Nos últimos dez anos, as investigações e os debates envolvendo a educação jurídica foram consideravelmente ampliadas. Como questionou Warat (2004) e Lyra Filho (1980), foi a partir da década de 80 que surgiu a necessidade de estudar o ensino jurídico com base em outros paradigmas, com base na análise de interfaces com inovações pedagógicas e desafios para o ensino do direito.

Lamy Filho assevera que a crise no ensino jurídico precedeu as demais crises, uma vez que há décadas os estudantes se queixam do ensino demasiadamente teórico, cujo aprendizado ministrado não os prepara para o desempenho e efetivo exercício da profissão. Além disso, os próprios professores do curso jurídico se inserem nessa crise, uma vez que, muitas vezes, lidam com alunos desinteressados e se obrigam a cumprir apressadamente um “currículo mínimo" (1972, p.4).

Para a compreensão de como se desenvolveu o diagnóstico da crise na educação jurídica no Brasil, necessário analisar alguns marcos históricos que aconteceram ao longo do tempo, que resultaram nas mudanças no ensino jurídico até os dias atuais.

Com a crise instaurada, o Ministério da Educação instaurou uma Comissão de Especialistas de Ensino de Direito, em 1980, com a finalidade de verificar a organização e o funcionamento dos cursos de Direito a nível de território nacional, composta de professores selecionados das mais diversas regiões do país. Essa comissão teve como proposta a divisão da matriz curricular dividida em quatro grupos de disciplinas, de matérias básicas, de formação geral, de formação profissional e de habilidades específicas. Também previa a criação do Laboratório Jurídico para a prática do estágio de 600 horas-atividade. Esse projeto elevava a carga horária do curso, e o prazo total de duração deveria ser de, no mínimo, cinco anos, e no máximo sete anos. Porém, essa proposta acabou sendo esquecida no plano político, não havendo qualquer decisão pelo Conselho Federal de Educação (RODRIGUES e JUNQUEIRA, 2002, p. 33).

Nessa linha, Rodrigues e Junqueira recordam que a preocupação com a crise da educação jurídica afetou a Ordem dos Advogados do Brasil, que, por meio da Comissão de Ensino Jurídico, tinha como função inicial realizar o levantamento de dados suficientes para avaliar a situação do Ensino Jurídico e, ainda, ao próprio mercado de trabalho para os advogados. A OAB, então, apresentou como diretrizes: a) a reforma de currículo deve ser acompanhada do engajamento dos professores e estudantes, de mudanças de atitudes e comportamentos pedagógicos; b) elaboração de diretrizes curriculares, com a participação de 
especialistas de todo o país, a fim de servirem como modelo recomendável aos cursos jurídicos; c) o currículo do curso jurídico deve ser tridimensional, abrangendo disciplinas de formação geral, disciplinas profissionalizantes e atividades práticas; d) Além das disciplinas, o curso deve oferecer outras atividades a serem desenvolvidas pelo aluno, como monitoria, iniciação científica, extensão, participação em congressos e demais eventos, dentre outras diretrizes traçadas (2002, p. 33-34).

Haviam múltiplas opiniões sobre o assunto, seja da comunidade acadêmica, seja das instituições e classes profissionais, geralmente, aqueles interessados no ensino jurídico brasileiro. O Ministério da Educação editou, assim, a Portaria n. 1.886/94, que merece destaque por ter sido um dos principais instrumentos para a regulamentação das diretrizes do ensino jurídico.

Como ressaltam Santos e Morais (2007, p. 65-66), a Portaria 1.886/94 teve como escopo uma série de modificações nos valores sociais, humanos e políticos, que, no entendimento dos autores, seriam alcançados a partir de eixos. Nesse viés, o primeiro, seria o eixo que os autores denominam de propedêutico, composto por conteúdos como filosofia, introdução ao Estudo do Direito, sociologia, ética, ciência política, etc. O segundo, seria o eixo profissionalizante, que tinha como objetivo primordial, dar conta do conjunto de especialidades peculiares à atuação jurídica, abrangendo ramos do direito como constitucional, administrativo, civil, penal, tributário, trabalhista e processual. O terceiro eixo, seria o que os autores intitulam como prático, que diz respeito a atividades de estágio supervisionado. Por fim, o quarto eixo seria o flexível, consistente na fixação de uma carga horária específica para a integralização curricular, na participação do aluno em atividades de ensino, pesquisa e extensão.

Várias foram as modificações trazidas pela Portaria 1.886/94 do MEC, de modo que, em especial, destacam-se as seguintes: a) exigência de monografia final orientada, defendida perante banca, como requisito essencial para a conclusão do curso; b) a fixação de carga horária mínima de 300 horas-atividade para o estágio curricular; c) a definição de que o estágio deve ser integralmente dedicado a atividades práticas, reais ou simuladas; d) a exigência de que o estágio ensinasse as atividades profissionais básicas; e) inclusão da Filosofia e da Ciência Política e a obrigatoriedade do estudo da Ética; f) ampliação da carga horária de 2700 horas para 3300 horas, com duração mínima de cinco anos e máxima de oito 
anos; g) a obrigatoriedade de que o currículo deveria envolver atividades de ensino, pesquisa e extensão de forma integrada, dentre outras (INEP, 2019).

Entretanto, a referida portaria foi editada, precedida de constantes discussões sobre as crises e problemas do Ensino do Direito no Brasil. Como destaca Rodrigues e Junqueira, as edições da Portaria 1.886/94 teve como pressuposto um grave erro histórico: "acreditar que o Direito pode mudar a realidade, quando ele pode, no máximo, ser um indutor da mudança e, mesmo assim, desde que outras condições (volitivas, materiais, psicológicas, culturais, etc.) mais importantes estejam preenchidas" (2002, p. 51).

Outras foram os atos normativos envolvendo o ensino do Direito, como a Resolução 09/2004, a Portaria MEC 2.477/2004 e a Portaria 1.874/2005. Porém, nenhuma delas foi eficaz para acabar com a crise existente na educação jurídica no Brasil. Neste sentido, Rodrigues e Junqueira concebem tal fato a partir de duas hipóteses: a primeira, refere-se à premissa de que as reformas nos atos regulamentadores feitos até hoje não foram adequadas aos problemas apresentados no ensino jurídico; e a segunda, diz respeito à questão preocupante que o Ensino do Direito no país não está resumido a aspectos curriculares. A partir deste entendimento, tem-se que acabar com a crise no Ensino do Direito por meio de uma simples alteração no currículo do curso ou nas diretrizes de uma matriz é equivocado.

Lamy Filho afirma que a crise no ensino jurídico foi a que precedeu as demais. Exemplificando, o autor menciona que "há décadas os estudantes se queixam que o ensino é "teórico" que o aprendizado que lhes é ministrado não os prepara para o desempenho da profissão" [...] "que os professores são, na maioria, desinteressados, e, alguns, até incompetentes, e, na quase totalidade, sem tempo para dedicar ao ensino e ao aluno". Contudo, no âmbito do corpo docente, o panorama também é desanimador: professores que "lidam com alunos desinteressados, estão obrigados a cumprir, apressadamente, um currículo enciclopédico a que chamam "currículo mínimo" (1972, p. 152). Ainda, necessário destacar outros fatores que contribuem para o estágio da crise no Ensino do Direito: a multiplicação de cursos, a consequente dificuldade de recrutar bons professores, cursos noturnos frequentados por alunos que estudam cansados da lida diária, onde alunos e mestres são solidários na procissão de queixas (LAMY FILHO, 1972, p. 152).

Pode-se afirmar, a partir desse diagnóstico de crise na educação jurídica, assim como afirma Streck (2017) ao criticar a literatura jurídica facilitada-resumida-simplificada, que o ensino jurídico brasileiro "produz uma blindagem, de modo que sua alienação é tamanha ao 
ponto de impedir o desenvolvimento de qualquer senso crítico". De forma opinativa, Campelo Filho (2017) afirma que o ensino jurídico no Brasil necessita ser (re)pensado, de forma a tratar do futuro do país, preparando pessoas para a pós-modernidade, enfrentando novos desafios que emergirão de uma sociedade cada vez mais global e complexa.

O Direito configura-se como um instrumento de regulação e controle social, que, mediante um sistema de normas, destina-se à solução de conflitos sociais. Essa ciência, todavia, vem sendo ensinada aos estudantes inserida em uma grave crise. Para Rodrigues (1993), a crise do ensino jurídico se expressa pelas atuais práticas adotadas pelas faculdades de Direito, onde "o ensino não vai além de indicar aos alunos a regra material que o Estado prevê para conflitos [...] e o consequente caminho para sua efetivação pelo juiz.

A crise da educação jurídica reflete em uma série de fatores, como, de forma direta, na qualidade do ensino do Direito nas faculdades, nos índices de aprovação no Exame da Ordem, o desinteresse dos alunos pelas aulas teóricas ministradas presencialmente, e, consequentemente, no desinteresse dos próprios docentes ao lidar com alunos desinteressados pela aula magistral dialogada e ativa diante as inúmeras facilidades de acesso ao conteúdo proporcionada pela globalização, bem como pela onda de cursos preparatórios de alunos para a aprovação em concursos públicos.

O resultado dessa crise se verifica no próprio mercado de trabalho. Para Rodrigues (1993, p. 25), “a maioria dos bacharéis em Direito nunca irá exercer essa profissão liberal”. Além disso, comenta o autor, na era contemporânea, a maioria daqueles que buscam cursos jurídicos de especialização almejam apenas o diploma, na busca da titulação necessária para a realização de uma série de concursos para cargos melhores remunerados, além do status social que algumas profissões jurídicas já não ostentam.

A oferta de cursos de Direito no Brasil vem crescendo a cada ano. Conforme dados do Instituto Nacional de Estudos e Pesquisas Educacionais Anísio Teixeira - INEP, por meio da elaboração das Sinopses Estatísticas da Educação Superior, extraídos do relatório Exame de Ordem em Números elaborado pela Fundação Getúlio Vargas em 2014, é possível verificar a expansão, entre 1977 e 1995, de um total de 108 novos cursos, o que significa uma média de seis novos cursos de Direito por ano. Entre 1995 e 2011, foram criados 55 novos cursos por ano, totalizando 1.121 cursos de Direito ao final deste período. De 2011 a 2012, o número passou a 1.158, ou seja, houve a criação de 38 novos cursos de Direito em um único ano. Ressalta-se que o crescimento do número de cursos de Direito é maior no âmbito das 
instituições privadas (FGV, 2014). O gráfico ilustra a evolução do número de cursos de Graduação em Direito ao longo dos anos.

Gráfico 1 - Evolução do crescimento dos cursos de Graduação em Direito

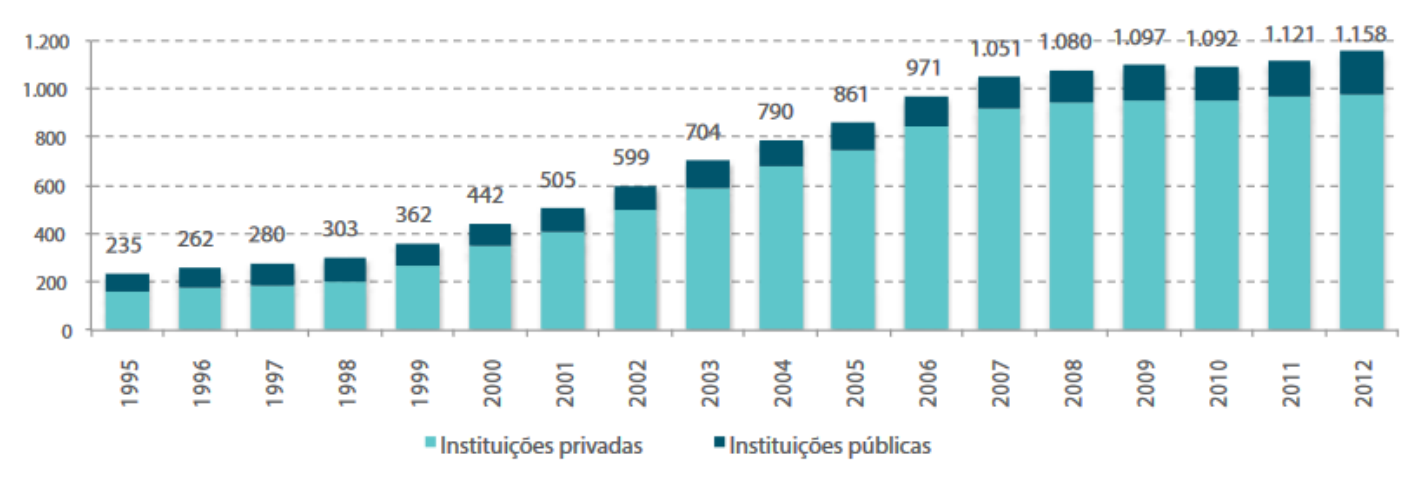

Fonte: Sinopses Estatísticas da Educação Superior - Inep. Elaboração: FGV Projetos

Nesse sentido, "a proliferação dos cursos de Direito sem obediência os critérios fixados pelo próprio MEC, nos moldes de verdadeiras empresas capitalistas de ensino superior, não é mais do que elemento conjuntural reforçador da crise de identidade" (ARRUDA JR, 1988, p. 72-73).

Outro aspecto relevante que configura um reflexo da crise na educação jurídica diz respeito ao número de reprovados no Exame da Ordem dos Advogados do Brasil. Desde 2014 o MEC e a OAB vêm inspecionando os cursos de Direito do país por meio de visitas presenciais, como uma medida para frear a expansão sem qualidade do ensino jurídico. Esse projeto é o resultado ao alto índice de repetência de estudantes no referido exame, sendo que em muitos casos as reprovações são oriundas do mesmo leque de instituições (OAB, 2014).

Apesar da Constituição Federal garantir o livre exercício de qualquer trabalho, ofício ou profissão (BRASIL, 1988), o Exame de Ordem constitui uma qualificação profissional estabelecida legalmente, conforme previsão do Estatuto da Advocacia e da OAB - Lei 6.906 de 04 de julho de 1994, que estabelece que o exercício da advocacia no território brasileiro e a denominação de advogado são privados dos inscritos na Ordem dos Advogados do Brasil, sendo que, para a inscrição como advogado, dentre seus requisitos, está a necessidade de possuir diploma ou certidão de graduação em Direito, obtido em instituição de ensino oficialmente autorizada e credenciada e a aprovação em Exame de Ordem (BRASIL, 1994). 


\section{A TRANSFORMAÇÃO DA EDUCAÇÃO JURÍDICA NO SECULO XXI: A FORMAÇÃO DAS COMPETÊNCIAS PROFISSIONAIS DOS OPERADORES DO DIREITO}

O Exame da Ordem tem como principal objetivo avaliar o bacharel em Direito para o exercício profissional, de forma a aferir se está apto e apresenta conhecimento teórico e prático indispensável ao exercício da advocacia.

Conforme estatísticas de desempenho dos resultados dos exames constantes no Relatório Exame da Ordem em Números da Fundação Getúlio Vargas de 2016, demonstrou que da II à XVII edição do exame da ordem, foram contabilizadas 1,91 milhão de inscrições, o equivalente à média de 119 mil inscritos por edição e 359 mil por ano. No referido intervalo de tempo, 639 mil pessoas participaram das provas, de modo que 360 mil examinandos (56\%) foram aprovados no Exame de Ordem (FGV, 2016). O gráfico abaixo ilustra a evolução do número de inscritos e aprovados por edição do certame:

Gráfico 2 - Evolução do número de inscritos e aprovados por edição do Exame da OAB
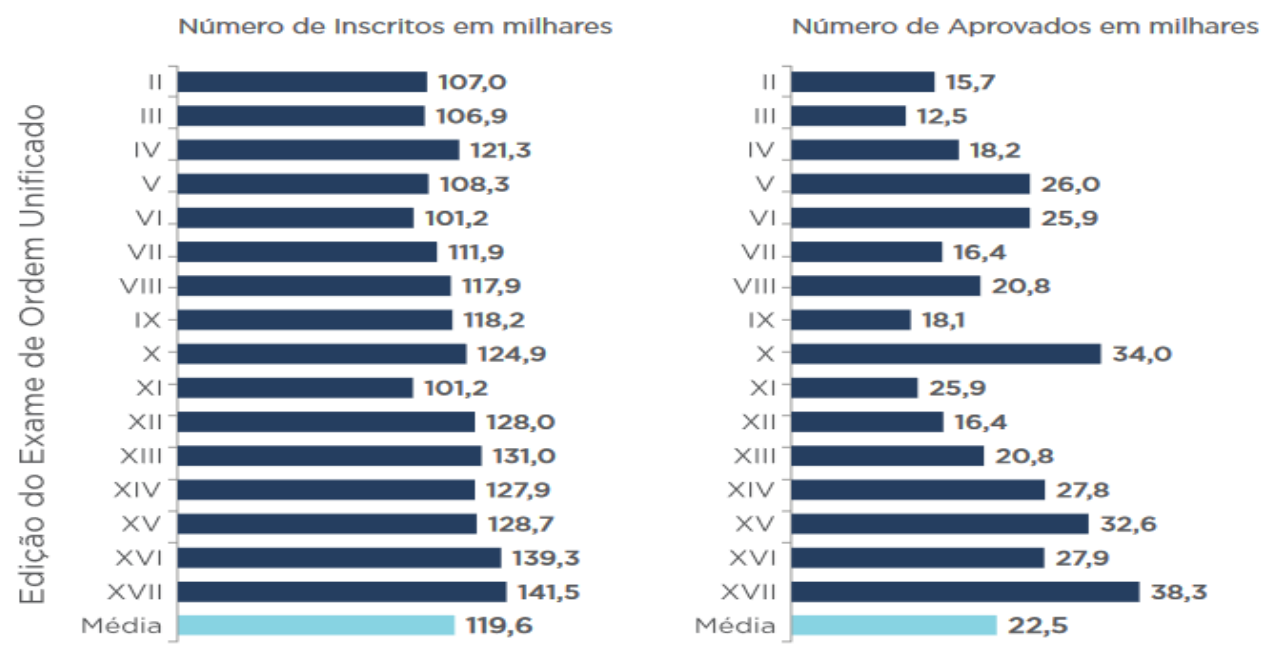

Fonte: FVG Projetos

A identificação de cada examinando pelo número de seu CPF permite avaliar e filtrar o desempenho com base no número de participações no Exame de ordem. A pesquisa aponta que no período da II até a XVII edição do exame, apenas 30\% dos examinandos foram aprovados na prova na primeira vez. Uma das possíveis hipóteses para justificar essa relação está associada à melhor formação e preparação dos examinandos que são aprovados logo na primeira tentativa. Na medida que são necessárias novas tentativas, restam indivíduos cada vez menos preparados para atender as exigências do Exame, o que explica o menor aproveitamento (FGV, 2016). 
Esses dados demonstram a situação crítica que a educação jurídica se encontra atualmente, exigindo um urgente repensar de suas diretrizes. Esse modelo merece ser revisto, com a finalidade de aperfeiçoar e promover a qualidade do ensino jurídico no Brasil. Não foi à toa que a $\mathrm{OAB}$ solicitou a suspensão da autorização para abertura de novos cursos de graduação em Direito pelo prazo de cinco anos, até de que se verifique a qualidade daqueles já existentes no país (OAB, 2019).

A preocupação com o elevado número de cursos de Direito autorizados nos últimos anos, a precariedade de determinas instituições que oferecem ensino jurídico, o elevado número de reprovados no Exame de Ordem e a repetência na sua realização torna necessário um novo paradigma. Rodrigues (1993, p. 27), ao analisar a área jurídica, destaca que os bacharéis são prioritariamente absorvidos pelo Estado em atividades não-jurídicas, enquanto muitos dos que estão inscritos na $\mathrm{OAB}$ não exercem a profissão. Uma série de outros a exerce apenas subsidiariamente, como uma atividade paralela à principal e que visa completar a sua renda.

Vislumbra-se assim, que o diagnóstico da crise na educação jurídica reflete tanto na qualidade do ensino jurídico oferecido nos cursos de graduação do país, como de forma direta no mercado de trabalho e na vida profissional e pessoal dos participantes de um mercado em saturação. Assim, diagnosticada a crise da educação jurídica, trágica realidade que se manifesta ao longo dos anos, passa-se ao segundo tópico do presente estudo, direcionado a compreender as novas premissas da sociedade globalizada em rede estabelecida nos dias atuais.

\section{AS NOVAS PREMISSAS: A SOCIEDADE GLOBALIZADA EM REDE}

O fenômeno da globalização tornou-se objeto de discussão nos debates modernos, sendo debatido a partir de suas dimensões que possuem características políticas, culturais, econômicas e também jurídicas. A partir da década de 70 o mundo passou por uma série de transformações significativas que reconfiguraram a economia, e consequentemente a política e a própria sociedade contemporânea.

Passou a emergir uma noção de "aceleração do mundo", uma vez que a globalização fez surgir a percepção de que o mundo parece ter encolhido - já que distâncias parecem ter ficado menos, tendo em vista que já não se levam mais meses para ir de um continente para 
outro - e, ainda, que o tempo parece andar mais rápido, onde tudo é aqui e agora. A rapidez com que os meios de comunicação, meios de transporte e instrumentos da informática e da telemática evoluíram ao longo dos últimos anos provocou transformações consideráveis no cenário nacional e até mesmo global (OLSSON, 2003, p. 91).

Para Santos (1998, p. 192), essa aceleração configura “[...] um resultado também da banalização da invenção do perecimento prematuro dos engenhos e de sua sucessão alucinante". Para o estudo desse fenômeno e da emergência da sociedade informacional e digital, De Fazio (2012, p. 30-31) considera que a revolução da tecnologia da informação “[...] realizou-se a partir da convergência de sucessivos eixos de transformações tecnológicas, que consistiram em inovações na microeletrônica, telecomunicações e computação [...]”, cujas mudanças se espalharam amplamente na década de 1970.

A globalização refletiu na crise do Estado, desestabilizando os mecanismos econômicos, sociais e jurídicos de regulação, estruturados há anos que hoje não mais se sustentam, emergindo a conhecida "crise de regulação" (ROTH, 1998, p. 17).

Essas mudanças ocorreram também no cenário jurídico. Isso porque, neste campo, a globalização promoveu uma integração jurídica intensa, proporcionando o acesso à justiça de forma destacada, na medida em que foram superadas as fronteiras territoriais para o exercício dos direitos dos cidadãos. Entretanto, como destaca Arnaud (1999, p. 19), a globalização proporcionou o desenvolvimento de um direito feição tradicional, de modo que "princípios, estratégias e normas de políticas de gestão da regulação" passaram a ser reconhecidos por todo o planeta.

Os reflexos do fenômeno globalizante no campo jurídico são marcados pelas próprias profissões jurídicas, que tendem a se transformar profundamente. Resultado dos avanços da tecnologia, barreiras físicas e operacionais foram superadas, criando-se sistemas eletrônicos que facilitaram o acesso à prestação jurisdicional. A globalização proporcionou, especialmente nos últimos anos, uma "justiça eletrônica" pautada na colaboração imediata, "não somente entre suas várias especialidades e grau, mas também com outros órgãos jurisdicionais estrangeiros ou supranacionais” (ZAMUR FILHO, 2011, p.35).

É inegável, portanto, que a globalização está diretamente ligada à emergência da era digital. Hoje, vive-se a era cibernética, marcada pela internet, transformando a sociedade e, por conseguinte, demandando mudanças nos limites e possibilidades da sua regulação pelo 
Direito. Essa nova realidade fez com que emergisse a ideia de que o ser humano vive em uma sociedade em rede.

Em sua obra, McLuhan já analisava as consideráveis transformações que assolaram a humanidade nos últimos séculos, afirmando que "as extensões do homem", pelos avanços da "era da eletrônica" já disseminavam em "meios quentes e frios", refletindo em diversos setores que fazem parte da vida em sociedade, como na economia, no comércio, na política. $\mathrm{O}$ impacto tecnológico fez com que emergisse um ambiente humano totalmente reconfigurado (McLUHAN, 2001, p. 10), que se apresenta nos dias atuais.

Trata-se, assim da chamada "era da informação". Castells (2006, p. 57) refere que a era informacional é o resultado do processo globalizante e dos avanços tecnológicos, de modo que é a partir dela que o processamento de dados ocorre de forma imediata, reconfigurando-se pelo surgimento de novos instrumentos que passam a fazer parte do mundo em redes globais de instrumentalidade.

A tecnologia encontra-se inserida nas relações interativas que ocorrem entre indivíduos e grupos, assim como o âmbito social do qual vivem, sendo que a cada momento lhes são oferecidas novas possibilidades de ação. Isso resulta na transformação da organização social, que se mostra cada vez mais conectada em rede (DE FAZIO, 2014, p. 345).

A sociedade em rede é característica da contemporaneidade, de modo que seu estudo demanda uma análise aprofundada. Reconhecer a sociedade em rede, de forma viva e pulsante, se faz fundamental para entender os limites e as possibilidades da organização social (OLSSON, 2016, p. 88), incluída, nesta organização, a esfera jurídica, como um dos reflexos da atual crise do ensino jurídico brasileiro.

Para Castells (2006, p. 566), “[...] redes são estruturas abertas capazes de expandir de forma ilimitada, integrando novos nós desde que consigam comunicar-se dentro da rede, ou seja, desde que compartilhem os mesmos códigos de comunicação". Ou, ainda, a rede pode ser conceituada como “[...] um conjunto de nós interconectados. Nó é o ponto no qual uma curva se entrecorta. Concretamente, o que um nó é depende do tipo de redes concretas de que falamos" (CASTELLS, 2006, p. 566).

Castells considera ainda as redes como estruturas comunicativas, processadoras de fluxos ou correntes de informação, que circulam os canais de conexão. Entende-se, assim, que as redes cooperam umas com as outras, e essa cooperação se baseia na capacidade de comunicação em razão da "existência de códigos de tradução e interoperabilidade entre elas". 
As redes constituem "um modelo de vida", ou uma "nova morfologia social" presente na nossa sociedade, sendo que "[...] a difusão da lógica de redes modifica de forma substancial a operação e os resultados dos processos produtivos e de experiência, poder e cultura" (CASTELLS, 2015, p. 66-67).

Nesse aspecto, a Internet é a ferramenta mais utilizada no âmbito das redes, e sua utilização ocasiona a "[...] desfragmentação da comunicação que antes estava localizada dentro das fronteiras nacionais, atingindo o nível global transnacional". A Internet exerce um valioso poder sobre a comunicação, e constitui um dos mais importantes resultados dos avanços tecnológicos, com a criação de computadores, da web e dos softwares (SILVA, 2016, p. 249-250).

Com o surgimento da Internet, emergiu uma nova cultura, definida por Silva (2013, p. 119) como "virtualidade real". A internet e as redes sem fio foram responsáveis por fornecer aos aglomerados de mídia novos mercados voltados para a publicidade, transformando em mercadorias os meios de comunicação e a informação. Como exemplo, “[...] o YouTube, o Facebook e o MySpace [...] podem estar surgindo como pontos de conexão essenciais entre as redes de mídia, as redes autônomas de autocomunicação de massa, interesses comerciais [...] e atores políticos" (CASTELLS, 2015, p. 150). Nessa linha, cada vez mais produtos de mídia são distribuídos e consumidos de forma on-line, resultados da formação e utilização das redes sociais pelos usuários.

A globalização vem tornando o campo jurídico muito mais denso e multidimensional. Como "campo jurídico", entende-se "a articulação de instituições e práticas através das quais a lei é produzida, interpretada e incorporada às tomadas de decisões na sociedade". Esse espaço inclui profissionais da Justiça, como os estudantes, advogados, juízes e as faculdades de direito. Mas também pode ser ainda entendido como um "conjunto de todos os personagens que fazem, interpretam e aplicam a lei, transmitem conhecimentos jurídicos e socializam os jogadores que se encontram no jogo do campo" (DEZALAY e TRUBEK, 1998, p. 31 e p. 36).

No âmbito jurídico as transformações resultantes desses avanços ainda tomarão surpreendentes rumos, especialmente na atuação dos operadores do Direito. Para Arnaud (1999, p. 20), os escritórios de advocacia atuam no sentido de "sistematicamente projetar suas ações antes mesmo de empreendê-las e de solucionar amigavelmente os assuntos contenciosos 
entre as partes", optando, assim, por cada vez menos se utilizarem das vias tradicionais judiciárias ou administrativas das soluções dos conflitos.

Por meio da utilização dos modernos instrumentos tecnológicos, o Direito passou a adquirir precisão e claridade, de modo que as novas tecnologias associadas ao surgimento do computador e da internet mudaram completamente os métodos e a estrutura do pensamento dos juristas e dos operadores do direito (GARCIA, 2014, p.123). Hoje, vislumbra-se que "a sociedade não é estática, mas dinâmica", uma vez que seus processos de formação se encontram em contínua mutação, no qual "o principal vetor dessa aparente (ou proposital) instabilidade é a tecnologia" (GARCIA, 2014, p.107).

Pode-se dizer que, com a intensificação do fenômeno da globalização, "um novo mercado para as atividades jurídicas tem surgido" (DEZALAY e TRUBEK, 1998, p. 48). Olgiati (1998, p. 100), na mesma linha, considera que há uma "reconversão" das profissões jurídicas, que se manifesta em decorrência da “internacionalização do mercado e seu corolário, a invalidação das instituições do Estado Social que caracterizavam a regulação econômica de tipo fordista". As poderosas ordens sóciojurídicas, como, por exemplo, as companhias transnacionais, passaram a dominar o cenário jurídico, acarretando mudanças radicais no direito e na dinâmica das profissões jurídicas (OLGIATI, 1998, p.100).

A globalização e a sociedade em rede estão penetrando cada vez mais na vida humana e nos setores mais fundamentais da sociedade, chegando até a refletir na própria formação dos operadores do Direito. Até então, os cursos de graduação em Direito sempre foram oferecidos de forma presencial, sendo que a cogitação da modalidade de ensino à distância sempre foi refutada, principalmente pela $\mathrm{OAB}$. Contudo, reflexos das facilidades tecnológicas estão refletindo de forma direta no ensino jurídico. Conforme matéria jornalística publicada em 20 de agosto de 2019 pelo jornal Valor, o Ministério da Educação deu o primeiro passo para que a graduação em Direito na modalidade on-line seja aprovada, de modo que pelo menos cinco instituições que solicitavam autorização para ofertar o curso nessa modalidade receberão comunicados informando que os cursos haviam sido pré-selecionados e em breve, haverá visitas de avaliadores do próprio MEC. Em contrapartida, a OAB considera que o curso de graduação em Direito na modalidade on-line não é meio eficaz para a formação de advogados (VALOR, 2019).

Verifica-se, por fim, que a globalização e a sociedade em rede geram impactos no Direito, na vida dos profissionais e na própria formação dos juristas. Esse fenômeno está 
presente nos níveis mais fundamentais da sociedade, tendo em vista que os processos de transformação ultrapassaram a esfera das relações sociais, sendo visíveis também no mundo jurídico.

\section{UMA PROPOSTA DE REORIENTAÇÃO: A NOVA GESTÃo POR COMPETÊNCIAS PROFISSIONAIS}

A crise no ensino jurídico exige que a formação dos profissionais vá além da teoria e prática. Na mesma linha de pensamento de Freitas (2000, p. 2), “a educação deve ser trabalhada na expressão de formar cidadãos críticos e conscientes que, em decorrência desta percepção, possam [...] se pensarem enquanto seres de cultura e agentes transformadores", na busca de mudarem e influenciarem os demais indivíduos e o meio do qual estão inseridos.

Tem-se, assim, um grande desafio para os cursos de graduação em Direito: uma reformulação das políticas pedagógicas a fim de se estabelecer um novo paradigma. Esse novo modelo, como ressalta Paiva et al (2011, p. 357) deve ter o condão de romper com esse modelo imposto e ser capaz de formar profissionais humanistas de uma abordagem interdisciplinar, capazes de compreender os fatos jurídicos e seus reflexos sociais, desenvolvendo a habilidade de utilizar técnicas profissionais, aliando teoria e prática.

A formação do operador do Direito vai muito além do conhecimento teórico e da sua aplicação prática. $\mathrm{O}$ ensino jurídico deve habilitar o acadêmico desenvolver competências que serão necessárias durante sua trajetória profissional e também pessoal. Saber se relacionar interpessoalmente com as partes, advogados, servidores da justiça, juízes, promotores e demais operadores do Direito é um elemento essencial, de modo que conteúdos como cortesia, escuta ativa e educação merecem prevalecer nesse campo. Além desse relacionamento interpessoal, o profissional do Direito deve saber se relacionar com sociedade e a mídia, de forma a interagir com a sociedade civil, conhecendo seu funcionamento, sua estrutura e seus problemas sociais. É importante também que o profissional do Direito saiba, ao relacionar-se com terceiros, utilizar linguagem compatível com a condição e instrução dos envolvidos. Esses são alguns exemplos que, embora não esgotem a temática, ilustram a variedade e complexidade das competências profissionais exigidas aos operadores do Direito na era contemporânea. 
Tanto no mundo profissional como acadêmico, a palavra competência pode indicar múltiplos significados. Adota-se, contudo, a posição de Philippe Zarifian (1994), que compreende a competência com a capacidade das pessoas: capacidade de assumir iniciativas, de estar além dos padrões determinados, de dominar e compreender situações que estão em transformação, e, ao mesmo tempo, de ser responsável e reconhecido pelos outros.

De outro vértice, "competências representam combinações sinergéticas de conhecimentos, habilidades e atitudes, expressas pelo desempenho profissional, dentro de determinado contexto ou estratégia organizacional” (PIRES et al, 2005, p. 14).

A noção de competência está cada vez mais presente no ambiente acadêmico e no mundo do trabalho. Contudo, como ressalta Kunzer, atualmente, existe uma nova dimensão que confere um novo significado ao conceito de competência, a partir das mudanças ocorridas no mundo do trabalho, que a autora considera como "o domínio do conhecimento articulado ao desenvolvimento das capacidades cognitivas complexas, ou seja, das competências relativas ao domínio teórico" $(2019$, p. 3).

Nesse sentido, o ensino jurídico, visa o atendimento a um público com expectativas que podem variar no tempo e no espaço, de modo que deve ser conferido ao acadêmico um aprendizado que seja além do formativo no sentido teórico-operacional, mas que contribua no desenvolvimento de competências profissionais que atendam a sociedade em suas múltiplas instâncias (PAIVA et al, 2011, p. 358).

Kunzer (2019, p. 3) afirma que esse novo conceito de competência se apresenta de forma reestruturada, e "demanda forte articulação entre as dimensões psicomotora, cognitiva e afetiva (fazer, saber e ser), para que o domínio dos conhecimentos científicos-tecnológicos e sócio-históricos, adquirido através de extensa, continuada e bem qualificada escolaridade".

No campo da educação jurídica, Zimiani e Hoeppner (2008, p. 104) consideram que os cursos de graduação em Direito devem adotar instrumentos de ensino capazes de ampliar a consciência dos acadêmicos, para que estejam preparados para entender em que contexto a profissão será exercida e qual o sentido de suas ações e os reflexos que elas provocarão na sociedade.

Evidentemente, reunir todos esses saberes complexos em um modelo de educação profissional jurídica, de forma ampla e desde o início do ensino do Direito, constitui grande desafio do ponto de vista da construção do eixo formativo do operador do Direito. A formação profissional, então, deve considerar esses pressupostos e desenvolver os saberes 
necessários e complementares para o exercício de sua profissão específica, incorporando matriz de gestão por competências, na qual deverá desenvolver conhecimentos, habilidades e atitudes adequadas e suficientes para o pleno exercício da profissão em todos os seus desdobramentos, como técnico-jurídicos, sociológicos, administrativos, deontológicos e psicológicos.

Nesse sentido, Le Boterf (1999) entende que a competência a ser desenvolvida decorre da aplicação conjunta, na atuação profissional, de conhecimentos, habilidades e atitudes, representados pela sigla "CHA", que representam os três recursos ou as três dimensões da competência.

Como ressaltou Pires (2005, p. 17) ao descrever as dimensões da competência, utilizando-se dos conceitos de Durand (2000), Gagné et al (11988) e Sanchez (1997), o conhecimento pode ser compreendido como uma série de informações assimiladas e estruturadas pelo indivíduo, que lhe permitem "entender o mundo". Trata-se, assim, do saber que a pessoa acumulou ao longo da vida, e deriva da informação e do conjunto de dados. A habilidade está relacionada ao saber como fazer determinada coisa, ou, ainda, a capacidade de fazer uso produtivo do conhecimento, utilizando-se dele e aplicando em uma ação. Por fim, a atitude refere-se aos aspectos sociais e afetivos relacionados ao trabalho, isto é, estados complexos do ser humano que afetam seu comportamento em relação à pessoas, coisas e eventos. $\mathrm{O}$ efeito da atitude seria justamente a ampliação da reação positiva ou negativa de uma pessoa em relação a uma ação específica, da qual tem relacionado sentimentos, de modo que a atitude refere-se ao querer fazer. A figura abaixo ilustra as dimensões da competência.

Figura 1 - Dimensões da competência 


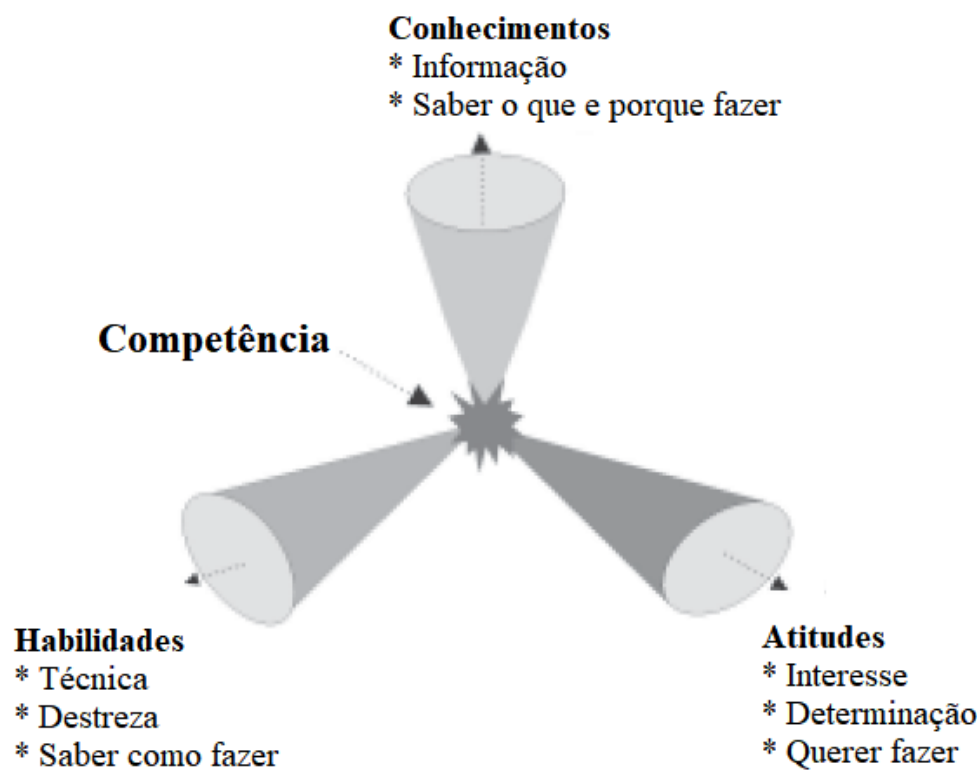

Fonte: Duran (1998), com adaptações.

A gestão por competências constitui uma nova proposta de reorientação, como possível solução à crise do ensino do Direito. Como um modelo de gestão, além do ensino teórico, é necessário para superar a falta de legitimidade dos operadores jurídicos. Como menciona Dalmo de Abreu Dallari, o ensino jurídico deve ir além da formação de um profissional manipulador de um processo técnico, formalista e limitado às finalidades imediatas (1985, p.1).

Necessita-se, assim, de uma mudança paradigmática do ensino do Direito, pautada na gestão de competências, que explorem no ensino jurídico as dimensões do conhecimento, da habilidade e da atitude. A mudança paradigmática para a afirmação da essencialidade da formação profissional com base nas competências, em complemento à prévia formação acadêmica revela grande potencialidade para qualificar o operador do Direito em torno de suas competências profissionais exigidas.

Por fim, somente a partir de novas estratégias será possível repensar a educação jurídica, uma vez que "não há como mudá-la estruturalmente se não se revolucionar o próprio conhecimento dominante sobre o Direito" e, ainda, nas estratégias deste ensino. Para Rodrigues, "mudanças cosméticas não bastam. É necessário implodir a estrutura existente e construir uma nova" (1993, p. 134).

\section{CONSIDERAÇOES FINAIS}


A partir do presente estudo foi possível verificar que hoje, se instaura uma grave crise na educação jurídica brasileira. Manifestada pelo elevado número de cursos de graduação em Direito aprovados nos últimos anos, pelos índices preocupantes apontados nas pesquisas quanto ao número cada vez mais crescente de reprovados no Exame de Ordem, e, ainda, pela quantidade de profissionais formados em Direito que estão desempregados ou que optaram por se inserir no mercado de trabalho em área não-jurídica, a investigação dessa temática apresenta-se relevante e incitante diante da trágica realidade que se verifica atualmente no Brasil.

Foi possível compreender ainda que a globalização foi determinante para a emergência da sociedade em rede, e as modificações desse fenômeno refletem nos setores mais fundamentais da sociedade, em especial, no Direito. Esses reflexos estão atingindo inclusive o a educação jurídica, que pode vir a sofrer modificações negativas pela influência da tecnologia, no sentido de transformar a educação presencial em educação à distância.

Este artigo induz como possível solução à crise da educação jurídica a instituição de uma gestão por competências, enquanto uma nova proposta de reorientação. Como um modelo de gestão, além do ensino teórico, é necessário para superar a falta de legitimidade dos operadores jurídicos. Necessita-se, assim, de uma mudança paradigmática do ensino do Direito, pautada na gestão de competências, que explorem no ensino jurídico, conjuntamente, as dimensões do conhecimento, das habilidades e das atitudes.

A mudança paradigmática para a afirmação da essencialidade da formação profissional com base nas competências, em complemento à prévia formação acadêmica revela grande potencialidade para qualificar o operador do Direito em torno de suas competências profissionais exigidas e, ainda, para possivelmente, superar a crise que assola a educação jurídica no século XXI.

\section{REFERÊNCIAS}

ARNAUD, André-Jean. O direito entre modernidade e globalização: lições de filosofia do direito e do estado. Tradução de Patrice Charles Wuillaume. Rio de Janeiro: Renovar, 1999. ARRUDA JR, Edmundo Lima de. Advogado e mercado de trabalho. Campinas: Julex, 1988. 
BRASIL. Constituição da República Federativa do Brasil de 1988. Disponível em: http://www.planalto.gov.br/ccivil_03/constituicao/constituicao.htm. Acesso em: 28 ago. 2019.

BRASIL. Lei 8. 906 de 04 de julho de 1991. Disponível em:

http://www.planalto.gov.br/ccivil_03/Leis/L8906.htm. Acesso em: 28 ago. 2019.

CASTELLS, Manuel. A sociedade em rede. São Paulo: Paz e Terra, 2006.

CASTELLS, Manuel. O poder da comunicação. Tradução Vera Lucia Mello Joscelyne. São Paulo: Paz e Terra, 2015.

CAMPELO FILHO, Francisco Soares. O advogado e a sua formação: é preciso (re)pensar o ensino jurídico no Brasil. 2017. Disponível em: https://www.conjur.com.br/2017-ago19/campelo-filho-preciso-repensar-ensino-juridico-brasil. Acesso em: 20 ago. 2019.

DALLARI, Dalmo de Abreu. Elementos de teoria geral do Estado. 11 ed. São Paulo: Saraiva, 1995.

DANTAS, San Tiago. A educação jurídica e a crise brasileira: aula inaugural dos cursos da Faculdade Nacional de Direito. Disponível em: https://www.santiagodantas.com.br/wpcontent/uploads/A-Educa\%C3\%A7\%C3\%A3o-Jur\%C3\%ADdica-e-a-Crise-Brasileira.pdf. Acesso em: 15 ago. 2019.

DEZALAY, Ives; TRUBEK, David M. A reestruturação global e o direito. In: FARIA, José Eduardo. (Org.). Direito e globalização econômica: implicações e perspectivas. 2 ed. Malheiros Editores: São Paulo, 1998, p. 29-80.

DE FAZIO, Marcia Cristina Puydinger. A sociedade civil global e a rede: resistência à globalização desde cima? Ijuí: Unijuí, 2012.

DE FAZIO, Marcia Cristina Puydinger. Protagonismos e cenários dos movimentos sociais globais: atores não estatais de resistência e o poder das redes. In: OLIVEIRA, Odete Maria de (Org.). Relações internacionais, direito e poder: cenários e protagonismos dos atores não estatais. vol I. Ijuí: Unijuí, 2014, p.323-364.

FREITAS, Neisser. O. Ensaio sobre a educação brasileira e o ensino jurídico: o ensino jurídico na graduação. Revista OAB Goiás, ano XIV, n. 42, abr./jun. 2000. Disponível em: <http://www.oabgo.org.br/Revistas/42/juridico_42.htm>. Acesso em: 20 ago. 2019

FUNDAÇÃO GETÚLIO VARGAS. Exame de ordem em números. v. III. Disponível em: https://fgvprojetos.fgv.br/sites/fgvprojetos.fgv.br/files/oab_3_edicao_v4_web_espelhado.pdf. Acesso em: 22 ago. 2019.

GARCIA, André Pinto. Certificação digital: da sociedade da informação às assinaturas eletrônicas. In: COÊLHO, Marcus Vinicius Furtado; ALLEMAND, Luiz Cláudio (Coord.). Processo judicial eletrônico. Brasília: OAB, Conselho Federal, Comissão Especial de Direito da Tecnologia e Informação, 2014. 532 p. - Disponível em <www.oab.org.br/publicacoes/download?LivroId=0000000466> Acesso em 20 out. 2015. 


\section{INSTITUTO NACIONAL DE ESTUDOS E PESQUISAS EDUCACIONAIS ANÍSIO} TEIXEIRA. Censo da Educação Superior. Disponível em:

http://portal.inep.gov.br/web/guest/educacao-superior. Acesso em 20 ago. 2019.

KUNZER, Acacia Zeneida. Conhecimento e competências no trabalho e na escola. Disponível em:

https://servicos.educacao.rs.gov.br/dados/seminariointernacional/acacia_kuenzer_conhec_co mpet_trab_esc.pdf. Acesso em: 30 ago. 2019.

LAMY FILHO, Alfredo. A crise do ensino jurídico e a experiência do CEPED. Revista do Instituto dos Advogados Brasileiros. Rio de Janeiro, v. 06, n. 18, p. 151-164, 1972.

Disponível em:

https://bibliotecadigital.fgv.br/dspace/bitstream/handle/10438/10396/Cadernos\%20FGV\%20 Direito\%20Rio\%20-

$\%$ 20Edi\%C3\%A7\%C3\%A3o\%20Especial\%20Alfredo\%20Lamy\%20Filho.pdf. Acesso em: 16 ago. 2019.

LE BOTERF, Guy. Competénce et navigation professionnelle. Paris: Éditions d’órganisation, 1999.

LYRA FILHO, Roberto. O direito que se ensina errado (sobre a reforma do ensino jurídico). Brasília: Centro Acadêmico de Direito da UnB, 1980.

McLUHAN, Marshall. Os meios de comunicação como extensão do homem. Tradução Décio Pignatari. 5 ed. São Paulo: Cultrix, 2001.

OLSSON, Giovanni. Relações Internacionais e seus atores na era da globalização. Curitiba: Juruá, 2003.

OLSSON, Giovanni. O poder da sociedade em rede e os atores não estatais. In: OLIVEIRA, Odete Maria de (Org.). Relações Internacionais, direito e poder: atores não estatais na era da rede global. volume III. Ijuí: Unijuí, 2016, p.87-116.

OLGIATI, Vittorio. Direito positivo e ordens sócio-jurídicas. In: FARIA, José Eduardo. (Org.). Direito e globalização econômica: implicações e perspectivas. 2 ed. Malheiros Editores: São Paulo, 1998, p. 81-102.

ORDEM DOS ADVOGADOS DO BRASIL. [...] MEC e OAB inspecionam cursos de Direito. 2014. Disponível em: https://www.oab.org.br/noticia/26531/deu-no-jornal-docommercio-mec-e-oab-inspecionam-cursos-de-direito. Acesso em: 20 ago. 2019.

ORDEM DOS ADVOGADOS DO BRASIL. OAB pede a suspensão da abertra de cursos de Direito por cinco anos. Disponível em: https://www.oab.org.br/noticia/57440/oab-pede-asuspensao-da-abertura-de-cursos-de-direito-por-cinco-anos. Acesso em: 20 ago. 2019.

PAIVA, Kely César Martins de et al. Competências profissionais e interdisciplinaridade no Direito: percepções de discentes de uma faculdade particular mineira. Revista Educação e 
Pesquisa. São Paulo, v. 37, n. 2, p. 355-373, mai./ago.2011. Disponível em: http://www.scielo.br/pdf/ep/v37n2/v37n2a10.pdf. Acesso em 29 ago. 2019.

PIRES, Alexandre Kalil et al. Gestão por competências em organizações de governo. Brasília: ENAP, 2005.

RODRIGUES, Horário Wanderlei. Ensino jurídico e o direito alternativo: São Palo: Editora Acadêmica, 1993.

RODRIGUES, Horário Wanderlei; JUNQUEIRA, Eliane Botelho. Ensino do Direito no Brasil: diretrizes curriculares e avaliação das condições de ensino. Florianópolis: Fundação Boiteux, 2002.

ROTH, André-Noel. O direito em crise: fim do Estado Moderno. In: FARIA, José Eduardo. (Org.). Direito e globalização econômica: implicações e perspectivas. 2 ed. Malheiros Editores: São Paulo, 1998, p. 15-24.

SANTOS, André Leonardo Copetti; MORAIS, José Luis Bolzan de. O ensino jurídico e a formação do bacharel em direito: diretrizes político-pedagógicas do curso de direito da UNISINOS. Porto Alegre: Livraria do Advogado, 2007.

SANTOS, Milton. A aceleração contemporânea: tempo-mundo e espaço-mundo. In: DOWBOR, Ladislau; IANNI, Octavio; RESENDE; Edgar A. (Orgs.). Desafios da globalização. Petrópolis: Vozes, 1998, p. 191-198.

SILVA, Andreia Rosenir da. O protagonismo de gênero como ator não estatal e o importante papel da rede em seu cenário. In: OLIVEIRA, Odete Maria de. (Org.). Relações internacionais, direito e poder: atores não estatais na era da rede global. Volume III. Ijuí, Ed. Unijuí, 2016, p.231-282.

SILVA, Felipe Stribe da. Proteção da intimidade nas redes sociais da internet: uma revisão do conceito de intimidade como forma de adaptação de seu sistema de proteção para os indivíduos membros das redes sociais da internet. Revista Direitos Emergentes na Sociedade Global, v.2, n.1, jan.jun, 2013. ISSN 2316-3054 - (DOI): 10.5902/231630547221

STRECK, Lenio Luiz. Resumocracia, concursocracia e a "pedagogia da prosperidade". 2017. Disponível em: https://www.conjur.com.br/2017-mai-11/senso-incomum-resumocraciaconcursocracia-pedagogia-prosperidade. Acesso em: 20 ago. 2019.

VALOR. MEC inicia avaliação de cursos on-line de Direito, segundo instituições. Disponível em: https://www.valor.com.br/empresas/6398855/mec-inicia-avaliacao-de-cursosline-de-direitosegundo-instituicoes. Acesso em: 22 ago. 2019.

WARAT, Luis Alberto. Epistemologia e ensino do direito: o sonho acabou. Coordenadores Orides Mezzaroba, Arno Dal Ri Júnior, Aires José Rover e Cláudia Servilha Monteiro. Florianópolis: Fundação Boiteux, 2004. 
ZAMUR FILHO, Jamil. Processo judicial eletrônico: alcance e efetividade sob a égide da lei no 11.419, de 19.12.2006. Dissertação (Mestrado em Direito), Universidade de São Paulo, 2011.

ZARIFIAN, P. Compétences et organisation qualifiante en milieu industriel. In: MINET, F.; PARLIER, M. ; WITTE, S. La Compétence: mythe, construction ou réalité? Paris: Éditions L'Harmattan, 1994. p. 111-134.

ZIMIANI, Doroteu; HOEPPNER, Márcio. Interdisciplinaridade no ensino do Direito. Akrópolis, Umuarama, v. 16, n. 2, p. 103-107, abr./jun. 2008. 